\title{
Muscular Dystrophy: A Retrospective Evaluation of 15 Cases
}

\author{
Olcay Güngör, ${ }^{1}$ Cengiz Dilber ${ }^{2}$ \\ 'Department of Child Neurology, Necip Fazıl City Hospital, Kahramanmaraş, Turkey \\ 2Department of Child Neurology, Maraslife Hospital, Kahramanmaraş, Turkey
}

\begin{abstract}
Objectives: The aim of this study was to investigate the clinical and laboratory findings of patients followed up with a diagnosis of Duchenne muscular dystrophy (DMD).

Methods: This retrospective study included 15 boys diagnosed with muscular dystrophy at the Pediatric Neurology Department between July 2008 and July 2016. The presenting symptoms; level of aspartate aminotransferase (AST), alanine aminotransferase $(\mathrm{ALT})$, and creatine kinase (CK); ophthalmological findings; echocardiography (ECHO) results; findings on brain magnetic resonance imaging (MRI); genetic analysis results; and muscular biopsy findings were evaluated.

Results: The mean age of the patients was $5.2 \pm 2.3$ years (range: 11 months- 8 years) and the mean age at the onset of DMD was 4.1 \pm 2.2 years (range: 10 months- 6 years). The ALT level ranged between 67 and $527 \mathrm{IU} / \mathrm{L}$, the AST between 44 and $455 \mathrm{IU} / \mathrm{L}$, and the CK between 931 and 19,595 IU/L. The genetic analysis determined deletions in 12 (80\%) and duplications in 2 (13\%) patients.

Conclusion: Parents with a DMD-affected child should be provided with genetic counseling in order to make decisions about future pregnancies.

Keywords: Child; genotype; muscular dystrophy.

Please cite this article as "Gungor O., Dilber C. Muscular Dystrophy: A Retrospective Evaluation of 15 Cases. Med Bull Sisli Etfal Hosp 2018;52(1):47-50".
\end{abstract}

$\mathrm{D}$ uchenne muscular dystrophy (DMD) is the most common form of muscular dystrophy, with a reported incidence of 1 in 3.500 live male births. ${ }^{[1]}$ DMD is the result of gene mutations, deletions or duplications that cause a loss of function in the dystrophin gene on the $\mathrm{X}$ chromosome. The symptoms of DMD typically start before the age of 5 years. Children with DMD have difficulty running, jumping, and climbing stairs due to the involvement of the proximal muscle. They often use their hands to support the body when rising to a standing position from the floor or a chair (Gowers' sign). Children with DMD aged 5 years or less have a creatine kinase (CK) level that is 10 to 200 times greater than normal. Most patients die in their 20s due to cardiac failure and infection. Over time, cardiomyopathy develops in one-third of DMD patients. The standard treatment for DMD includes the use of corticosteroids and ataluren. ${ }^{[2-4]}$ The aim of this study was to investigate the clinical and laboratory findings of patients followed up with a diagnosis of DMD.

\section{Methods}

This retrospective study included 15 boys who were diagnosed with DMD at the Pediatric Neurology Department between July 2008 and July 2016. The diagnosis was established based on clinical signs and symptoms, serum CK measurements, genetic tests, and muscular biopsy find-

Address for correspondence: Olcay Güngör, MD. Department of Child Neurology, Necip Fazıl City Hospital, Kahramanmaraş, Turkey Phone: +90 5065020439 E-mail: drolcaygungor@gmail.com

Submitted Date: June 17, 2017 Accepted Date: November 17, 2017 Available Online Date: March 26, 2018

${ }^{\circ}$ Copyright 2018 by The Medical Bulletin of Sisli Etfal Hospital - Available online at www.sislietfaltip.org

This is an open access article under the CC BY-NC-ND license (http://creativecommons.org/licenses/by-nc/4.0/). 
ings. The presenting symptoms, parental consanguinity, neurological symptoms, genetic analysis findings, and the prognosis of the disease were recorded for each patient. An evaluation was made of brain magnetic resonance imaging (MRI) findings, ophthalmological findings, ECHO results, muscular biopsy findings, and the level of aspartate aminotransferase (AST), alanine aminotransferase (ALT), and CK. Mutations in the dystrophin gene were primarily identified using the multiplex ligation-dependent probe amplification (MLPA) method (SALSA MLPA probemix P034-A3/ P035-A3 DMD/Becker; MRC-Holland, Amsterdam, Netherlands), which enables the detection of deletions or duplications in all 79 exons. The data obtained were analyzed using Coffalyser MLPA analysis software (MRC-Holland, Amsterdam, Netherlands). For single exon deletion, further verification was performed with polymerase chain reaction (PCR) analysis and sequencing. ${ }^{[5]}$ The study was approved by the Ethics Committee. Informed consent was obtained from the parents of all the children.

\section{Results}

The 15 patients had a mean age of $5.2 \pm 2.3$ years (range: 11 months-8 years). The mean age at the onset of DMD was $4.1 \pm 2.2$ years (range: 10 months- 6 years). On physical examination, all of the children were within the normal percentiles for height, body weight, and head circumference. The parents of $2(13 \%)$ children had second-degree consanguinity. Three (20\%) children had a family history of DMD. MRI examination was performed on 5 (33\%) children and the findings were normal. One (7\%) child had epilepsy and was on antiepileptic treatment. Mild mental retarda- tion was detected in 1 (7\%) patient. In all of the patients, pseudohypertrophy was detected in the gastrocnemius muscle. Ten (67\%) children were on steroid treatment. Two (13\%) children had mild dilated cardiomyopathy. Three (20\%) patients had difficulty walking (Table 1). The ALT level ranged between 67 and $527 \mathrm{IU} / \mathrm{L}$, the AST level between 44 and $455 \mathrm{IU} / \mathrm{L}$, and the CK level between 931 and 19.595 IU/L. A genetic analysis was performed for each patient. The cases with no mutation identified on MLPA and denaturing high performance liquid chromatography were diagnosed as DMD on the basis of muscle biopsy indicating the absence of dystrophin expression and on clinical manifestations. Deletions were detected in the genetic analysis of 12 $(80 \%)$ patients, and duplications in $2(13 \%)$ patients (Table 2). In 1 patient, the genetic analysis result was negative; however, a muscle biopsy revealed a myopathic change (necrotic and regenerative muscle fibers) and the diagnosis was made based on the examination findings.

Table 1. Walking capability, medications, and intervention in the participants with Duchenne

\begin{tabular}{lc}
\hline Clinical Features & $\mathbf{n}(\%)$ \\
\hline Walking capability & \\
Normal walking & $12(80)$ \\
Not able to walk & $3(20)$ \\
Cardiac function & \\
Dysfunction & $3(20)$ \\
$\quad$ Normal & $12(80)$ \\
Steroid treatment & \\
Yes & $10(66.6)$ \\
No & $5(33.3)$ \\
\hline
\end{tabular}

Table 2. Confirmed point mutations, small deletion/insertion of Duchenne muscular dystrophy/Becker muscular dystrophy patients

\begin{tabular}{|c|c|c|c|c|c|c|c|c|}
\hline No. & Gender & Years & Phenotype & Family history & Exon/Intron & AST & ALT & CK \\
\hline 1 & $M$ & 6 & DMD & - & $8-17$ & 125 & 97 & 11234 \\
\hline 2 & $M$ & 11 months & DMD & + & $45-50$ & 527 & 234 & 9876 \\
\hline 3 & $M$ & 3 & DMD & - & $45-52$ & 98 & 128 & 16400 \\
\hline 4 & $M$ & 8 & DMD & - & $45-52$ & 305 & 203 & 12300 \\
\hline 5 & M & 7 & DMD & - & $12-42$ & 402 & 101 & 19595 \\
\hline 6 & $M$ & 7 & DMD & - & $45-50$ & 198 & 99 & 9870 \\
\hline 7 & $M$ & 6 & DMD & + & $48-52$ & 504 & 44 & 17500 \\
\hline 8 & $M$ & 3 & DMD & - & no & 104 & 455 & 7600 \\
\hline 9 & $M$ & 8 & DMD & - & $21-51$ & 67 & 157 & 13200 \\
\hline 10 & $M$ & 5 & DMD & - & $8-11$ & 124 & 202 & 10100 \\
\hline 11 & $M$ & 7 & DMD & - & $48-52$ & 142 & 403 & 931 \\
\hline 12 & $M$ & 6 & DMD & + & $48-52$ & 98 & 208 & 9680 \\
\hline 13 & $M$ & 8 & DMD & - & $45-50$ & 206 & 189 & 5700 \\
\hline 14 & M & 15 months & DMD & - & 45 & 201 & 76 & 11400 \\
\hline 15 & $M$ & 18 months & DMD & - & $45-50$ & 186 & 48 & 14000 \\
\hline
\end{tabular}

AST: Aspartate aminotransferase; ALT: Alanine aminotransferase; CK: Creatine kinase; DMD: Duchenne muscular dystrophy; M: Male. 


\section{Statistical Analysis}

Statistical evaluation of the data was performed using SPSS for Windows, Version 16.0 software (SPSS Inc., Chicago, IL, USA). Discrete variables (e.g., muscular biopsy findings, genetic analysis findings) were presented as number ( $n$ ) and percentage (\%) and continuous variables (e.g., age, height, body weight, echocardiography findings) were presented as mean $\pm S D$ and with median and minimum-maximum values, as needed. Paired comparisons between corrected independent groups were performed using the Student's $t$-test or the Mann-Whitney $U$ test. A value of $p<0.05$ was considered statistically significant.

\section{Discussion}

DMD and its milder form, Becker muscular dystrophy (BMD), are X-linked recessive forms of muscular dystrophy caused by mutations in the dystrophin gene on chromosome Xp21.2. ${ }^{[6,7]}$ The typical symptom of proximal muscle weakness often appears before the age of 5 years and cardiac involvement develops after muscular involvement. ${ }^{[8]}$ Consistent with the literature, in the current study, the mean age at the onset of DMD was $4.1 \pm 2.4$ years. It is commonly known that cardiac involvement occurs in $90 \%$ of DMD patients, depending on the stage of the disease, with subclinical cardiac involvement starting in the first decade, and cardiovascular symptoms appearing after the development of cardiomyopathy in the second decade. Preclinical cardiac involvement is present in $26 \%$ of patients aged less than 6 years, may be $62 \%$ in patients aged 6 to 10 years, and can be even greater in older children. ${ }^{[8,9]}$ Cardiac involvement was present in 2 patients in this study. This low rate of cardiac involvement may be attributed to the fact that the other patients were relatively younger and had not had routine cardiac screening. DMD and BMD affect 1 in 3.500 children. Therefore, a prenatal genetic diagnosis is highly recommended for families with a DMD- or BMD-affected child. In isolated cases, the risk of the mother being a carrier is $2 / 3(67 \%)$, so genetic counseling is crucial for those mothers considering another pregnancy. If pregnancy occurs, prenatal genetic testing is highly important for the fetus. Approximately one-third of isolated cases result from new mutations with no probability of carriership in the mother or other female relatives. DMD and BMD patients often present with gene deletions (60-65\%) or duplications (10-15\%). Currently, 2-layered multiplex PCR assay is the most widely used diagnostic method for the evaluation of exons where mutations are most frequently seen. ${ }^{[10-12]}$ In the current study patients, gene deletions were detected in 12 patients (80\%) and duplications in $2(13 \%)$, and 1 patient $(7 \%)$ was diagnosed by biopsy. The deletions were mostly detected between exons 45 and 52 , which was consistent with the literature. ${ }^{[10,13,14]}$ Some other studies have shown that patients with deletions observed between exons 45 and 47 have become unable to walk without support after the age of 15 to 20 years. ${ }^{[15]}$ In the current study, the oldest child was 10 years old and 3 patients (20\%) were unable to walk without support. The families of 3 patients had healthy babies after receiving genetic counseling. The provision of genetic counseling should be considered of the highest importance for the prevention of fatal disease, particularly in regions with a limited sociocultural context.

\section{Conclusion}

In conclusion, in a family with a DMD-affected child, carriership should be investigated in all family members. Genetic counseling and prenatal genetic testing should be provided for these parents in order to avoid fatal disease in future pregnancies.

\section{Disclosures}

Ethics Committee Approval: Approval:Ethical approval was obtained from the Hospital Ethics Committee of Sütçü İmam University, Faculty of Medicine (Number: 195).

Peer-review: Externally peer-reviewed.

Conflict of Interest: There are no known conflicts of interest associated with this publication and there has been no significant financial support for this work that could have influenced its outcome.

Authorship contributions: Concept - O.G.; Design - O.G., C.D.; Supervision - O.G.; Materials - O.G., C.D.; Data collection \&/or processing - O.G., C.D.; Analysis and/or interpretation - O.G.; Literature search - O.G., C.D.; Writing - O.G.; Critical review - C.D.

\section{References}

1. Sarnat H.B. Musculardystrophies. In: Berhman RE, Kliegman RM, Jenson HB, editor. Nelson Textbook of Pediatrics. 17th. Philedelphia: Saunders; 2004. p. 2060-69.

2. Hightower RM, Alexander MS. Genetic modifiers of Duchenne and facioscapulohumeral muscular dystrophies. Muscle Nerve 2018;57:6-15. [CrossRef]

3. Okubo M, Goto K, Komaki H, Nakamura H, Mori-Yoshimura M, Hayashi YK, et al. Comprehensive analysis for genetic diagnosis of Dystrophinopathies in Japan. Orphanet J Rare Dis 2017;12:149.

4. Araujo APQC, Carvalho AAS, Cavalcanti EBU, Saute JAM, Carvalho E, França MC Junior, et al. Brazilian consensus on Duchenne muscular dystrophy. Part 1: diagnosis, steroid therapy and perspectives. Arq Neuropsiquiatr 2017;75:104-113. [CrossRef]

5. Chamberlain JR, Chamberlain JS. Progress toward Gene Therapy for Duchenne Muscular Dystrophy. Mol Ther 2017;25:1125-1131.

6. Bello L, Pegoraro E. Genetic diagnosis as a tool for personal- 
ized treatment of Duchenne muscular dystrophy. Acta Myol 2016;35:122-127.

7. Davies KE, Smith TJ, Bundey S, Read AP, Flint T, Bell M, et al. Mild and severe muscular dystrophy associated with deletions in Xp21 of the human X chromosome. J Med Genet 1988;25:9-13. [CrossRef]

8. Finsterer J, Stöllberger C. The heart in human dystrophinopathies. Cardiology 2003;99:1-19. [CrossRef]

9. Dellafave LM, McNally EM. Cardiomyopathy in neuromuscular disorders. Progress in Pediatric Cardiology 2007; 24:35-46. [CrossRef]

10. Zhou J, Xin J, Niu Y, Wu S. DMDtoolkit: a tool for visualizing the mutated dystrophin protein and predicting the clinical severity in DMD. BMC Bioinformatics 2017;18:87. [CrossRef]

11. Kneppers AL, Ginjaar B, Bakker E. Duchenne and Becker Muscular
Dystrophy. In: Elles R, Mounthford R, editor. Molecular diagnosis of genetic diseases. 2nd. USA: Humana press; 2004.

12. McCabe ERB. Modifier genes: Moving from pathogenesis to therapy. Mol Genet Metab 2017;122:1-3. [CrossRef]

13. Huang X, Poy F, Zhang R, Joachimiak A, Sudol M, Eck MJ. Structure of a WW domain containing fragment of dystrophin in complex with beta-dystroglycan. Nat Struct Biol 2000;7:634-8. [CrossRef]

14. Muntoni F, Torelli S, Ferlini A. Dystrophin and mutations: one gene, several proteins, multiple phenotypes. Lancet Neurol 2003;2:731-40. [CrossRef]

15. Li X, Zhao L, Zhou S, Hu C, Shi Y, Shi W, et al. A comprehensive database of Duchenne and Becker muscular dystrophy patients (0-18 years old) in East China. Orphanet J Rare Dis 2015;10:5. [CrossRef] 